\title{
To be or not to be: Transformative Insights into the Paradox of Using English as the Language of Instruction in South African HE Institutions
}

\author{
P.B. Neo Maseko \\ Mgutshini Tennyson
}

\section{Abstract}

Universities and other institutions of higher education have been the focus of societal scrutiny in recent years with many critics arguing that they perpetuate rather than reduce inequalities amongst their learners. This allegation has been aligned by some, to the fact that literacy and numeracy competencies appear to be class or socio-economically determined and that these differences carry through until graduation and beyond. Significantly, rates of student dropout, attrition and post-graduation employability appear to be directly related to numeracy and literacy. With respect to the latter, literal competence is in effect being used as the yardstick measurement of learners' competence in the language of learning and teaching (LOLT), that is, English. Within South African higher education, the issue of literacy is particularly complicated by the fact that two competing view-points have been articulated namely, that disadvantage for the student can be minimized by offering university education in their mother tongue. The alternate view is based on the notion that the development of competence in English should be a primal focus for all educationalists and may serve as a panacea for the intractable problem of poor student success. A further contention of this alternate view is that English language proficiency has ramifications for students' graduateness and employability prospects. Against this background, the current paper focuses on this paradox as it relates to student success. This analysis specifically considers teaching and learning within Higher Education in the South African context from three language-related thematic perspectives namely, (i) cultural identity 
preservation; (ii) socio-economic mobility and (iii) global citizenry. These perspectives encompass the multi-layered paradoxes that form part of the Higher Education landscape in South Africa.

Keywords: Higher Education, South Africa, university transformation, instruction language, language literacy

\section{Introduction}

Universities have always been viewed as centres of knowledge production, initially by a select and privileged few for the consumption of the wider masses (Björkman 2011; Stone 2009). Early Universities typified this elitist identity by only allowing access to a limited, privileged breed of learner whose background, pedigree and social status ensured success by virtue of registration to their school of choice (Moeketsi \& Mgutshini 2014; Huisman et al. 2012). However, with the passage of time there has been a growing quest and concern for a more just society. This quest is best expressed within the seminally important Sustainable Development Goals (SDGs) (World Education Forum, 2015) and the globally adopted 2030 Education Framework which are based on the assertion that global development can only be achieved by ensuring inclusive and equitable quality education opportunities for all (UNESCO 2015).

This social justice agenda has served as an impetus for open access. Contemporary university structures are bound to more inclusive admission principles and with this massification of education, (Boden \& Nedeva 2010) the heterogeneity of the student population has brought with it benefits and challenges that play centre-stage roles in the current discourse about education. Success rates, student retention and attrition, and the concept of graduateness are but a few of the imperatives that pose the most notable of challenges to educators. Alongside the often-cited lack of numeric competence, the role of language in academic access and success continues to feature prominently in discourses of academic success.

\section{A Contextual Backdrop}

As pointed out in the introductory paragraph, completion continues to present itself as an elusive goal for university students. The long-standing focus on 


\section{P.B. Neo Maseko \& Tennyson Mgutshini}

massification and widening of access into Higher Education can only be meaningful if the access afforded to previously excluded populations is matched by equitable distribution of teaching and learning opportunities for all students. Higher Education institutions are facing an unprecedented challenge with regard to low pass and throughput rates. A study conducted by the Department Education (2005) shows that $31 \%$ of the 120000 students who enrolled in higher education dropped out during their second and third years. The fact that many students who enter HE institutions are destined for 'completion by-way of drop-out' or what some have infamously coined as the 'drop-out zone' has been a source of major concern. Within this picture of none completion, global studies suggest anything from 19\% to 50\% of all first year university students typically do not progress beyond their first year (McGregor 2014).

This prognosis is worse in some specific types of higher education institutions, for example, Open Distance Learning (ODL) institutions report higher rates of drop out by comparison to traditional contact university counterparts. As one of the world's largest open distance universities, the University of South Africa (UNISA) is faced with seminal challenges that negatively impact students' projected trajectory. For example, in 2006, the first-year dropout rate across all of its programs was $22.4 \%$, a statistic that suggested that nearly one in four students starting programs in the university dropped out within their first year of study (UNISA DISA 2012). In 2012, after a further six years of efforts to address non-completion and premature exit from study, the UNISA first-year average dropout rate ranges from $19.4 \%$ in PG Certificate/ diploma programmes to $45 \%$ (undergraduate certificate / diploma programmes) (UNISA DISA 2012). Notably, the relatively high first year dropout seen at UNISA typifies that of comparable Open Education Institutions and Online providers (Tait 2000; Yorke 2004; and Terry \& Poole 2011).

As many as a staggering three-quarters $(78 \%)$ of students across threeto four-year degree programs will not successfully complete their qualifications within the specified course-duration times. Only $9 \%$ of students doing three-year degrees will complete their studies within the specified three-year period. Similarly, $8 \%$ of those completing four-year degrees and $2 \%$ on threeyear diplomas complete their programs of study within the pre-determined completion times. UNISAs attrition and completion patterns occupy a unique significance for the South African HE landscape because the university accounts for $35 \%$, i.e. over a third of enrolment participation across the country 
(Statistics South Africa 2014). Outside of the contribution towards national student recruitment, UNISA's social justice mandate has specifically prioritized the engagement of students from previously marginalized social groups. This massification of $\mathrm{HE}$ brings with it heightened risks to attrition and poor throughput.

These patterns of attrition and low-student participation pose formidable challenges to the South African HE landscape. Scott (2014) concurs with this observation and further re-states that South Africa has a lowparticipation and poor attrition system that is characterized by heavy dropout patterns particularly in the first year of study.

\section{The Paradox of Language and Cultural Identity Preservation}

Dominated by an urgent need to correct previous societal injustices, South Africa, much more than any country in the world, has widely debated the significance of reinstating local languages as equals to English and other colonially derived languages. Nowhere else has this contestation received more attention than within academia where de-colonial scholarly discourse has posited unequivocally that, failure to offer education in learners' mothertongue represents a significant barrier particularly for the previously marginalized black learners. Beyond the representation of a significant source of exclusion, some including (Björkman 2011; Huisman et al. 2012; Martínez 2010) present evidence which cites this limitation as a noteworthy contributing factor in poor study-related outcomes for students. Within this viewpoint, there is wide agreement that the issue of academic success (or lack thereof) has largely been attributed to the language proficiency of students who are primarily second-language (L2) speakers of English and who find themselves in an academic environment where the language of learning and teaching (LOLT) is English. The ability to decode information in the form of academic texts such as module guides, text books, tutorial letters, etc., coupled with the expectation to critically encode texts that comply with academic writing standards, is often a seemingly insurmountable exercise for students and is particularly more problematic for those with lower levels of competence in English. Within this viewpoint, some including (Norton 2010; Grant \& Wong 2003; Seidel \& Moritz 2009) argue that the lower levels of English proficiency observed among L2 learners is a reflection of the interplay of a complex set of 


\section{P.B. Neo Maseko \& Tennyson Mgutshini}

class-related disadvantages. The basis of this asserted view centres on attributing observed shortcomings on many factors that are unrelated to learners' English competency. Supported by this conclusion, (Huisman et al. 2012; Short \& Fitzsimmons 2007; Hu \& Lei 2014) argue that depriving learners of the opportunity to learn in their mother tongue has such a negative impact on the learners sense of self-worth that it can, at times, be the sole reason for non-performance. Furthermore, proponents of mother-tongue instruction validly contend that the use of students' home-language would serve an ameliorative purpose in the attrition and retention dilemma. They further argue that if knowledge is 'packaged' in English it is exclusionary and denies adequate access to knowledge to those who do not have mastery of English as LOLT (UNESCO 2003).

\section{Language: An Economic Tool or a Form of Personal Identity?}

Wolff's (2005) assertion that in Africa, language is a very sensitive issue, mainly because of its history and neo-colonial relationship with former colonial powers, is instructive. Added to this is the notion of language as an emotive subject that is strongly linked to identity. Discussions around language use are often perceived as threats to the core of culture and they thus evoke a knee-jerk response of self-preservation. Thorpe (2002) concurs with this assertion by stating that African languages should receive attention in an African country. However, she points to the reality that in South Africa, English has a colonial past and a global future, with the result that there is a clash between ideology and reality (Thorpe 2002). In this instance, ideology is conceived of as the ideal of a counter-hegemonic strategy in the form of mother tongue instruction while the reality is the dominance of English in many spheres of the economic, education and social strata.

The reality is also that English has enjoyed historical hegemony and dominance as a currency in the knowledge economy of education. On the flip side there is the ideal of policy imperatives and situational dictates about the use of Home Language to facilitate access to knowledge reception and production. This constitutes a paradigmatic paradox that translates into another layer of the paradox, namely, the hegemony of English vis a vis policy dictates.

A further factor for consideration is the interplay between codification (Bernstein 1990) and meritocracy (McNamee \& Miller 2004) which ultimately has a bearing on employability (Boden \& Nevada 2010; Coetzee 2012). 
Bernstein (1990) points out the unfair advantage that is afforded to those whose privileged pre-university background exposed them to a code that is similar to that of the academia over those who did not get exposure to the academia's codification culture. This inequity invariably often leads to a further disadvantage resulting from the academia's system of meritocracy, which relies heavily on codification. Since English is the language of encoding information and the means towards access to epistemic knowledge this means that L2 speakers of English will often be out-performed by their L1 speaker counterparts. Alexander (2010) argues for mother tongue instruction as a counter-hegemonic strategy. In so doing he represents the school of thought that attaches a cultural significance to the issue of language.

However, Matentjie (2010), an educational psychologist, tacitly presents a counter-argument about this counter-hegemonic strategy in view of the complexities of bi-and multi-lingual familial contexts. According to her, the problem is compounded by the fact that in urban areas the variation of the mother tongue is often a 'diluted' and 'urbanised' version of the L1 used in rural areas. This means then that the urban speakers of the home language do not, in reality, have mastery of the home language, in its pure L1 form. She points out that a further challenge is that while the mother tongues function effectively at a BICS -Basic Interpersonal Communication Skills -level they have not yet been adequately developed to function effectively at a CALP Cognitive Academic Language Proficiency level (Cummins 1996). In a study conducted at various schools, Taylor (2013) through the National Education Evaluation and Development Unit (NEEDU) report, confirms the difficulty of, for example, teaching Mathematics using mother-tongues that still do not have the appropriate equivalents for Mathematical jargon. A further compounding factor noted by the report is that of the issue of the different dialects of the same language as determined by geographic location. Furthermore, the issue of non-familiarity with the official parlance is pointed out.

The afore-mentioned contextual realities are compounded by the fact that in ODL institutions there is a heavy reliance on access to technology as a vehicle for knowledge transfer and information dissemination. The socio-economic conditions of most of the L2 students often place them within the lowincome or economically deprived category. The ramifications of this reality are that technological access is more often than not, a challenge, thus resulting in a debilitating dose of double disadvantage, namely, limited technological access and what is termed as 'sub-standard' English language proficiency. 


\section{P.B. Neo Maseko \& Tennyson Mgutshini}

Since the ambit of this discussion is confined to language and literacy related factors, the technology-related factors will not be explored. The focus of this discussion is thus academic language, which is regarded as the currency of knowledge production (encoding of texts) and reception (decoding of texts). This paper supports the view posited by Okombo (2000) that no matter how we define development, it cannot be done comprehensively without referring to language. He further highlights the familiar fact that, in the former British colonies of Africa, there is a heavy reliance on knowledge and information that is packaged in English. This creates a language barrier, which makes knowledge inaccessible to a large number of people.

For this afore-mentioned reason the argument in this paper is, therefore, to consider the need for an approach that will empower students to access and decipher knowledge that would otherwise be packaged in inaccessible (to them) texts. In order for knowledge to be accessible it has to be presented in a language that can be understood. For L2 speakers of English this language would be their Home Language. However, the reality is that as Thorpe (2002) points out in tacit affirmation of Okombo's (2000) assertion, English is the language of power, which is used in education, parliament and the corporate world. The assertion is validated by Nicherson (2005) when she notes that English has made an unprecedented rise to become the world's lingua franca, the most commonly used language of global trade. Acknowledgement and confirmation of English as the language of commerce underscores the critical importance that it carries in the future of graduates who need to be employed in their specific disciplines within South Africa and beyond.

\section{Social Economic Mobility in Relation to Graduateness and Employability}

There is a link between success and the concept of graduateness, with the latter being closely aligned to employability. Barrie (2006) supports this with the view that the competencies and attributes that a graduate should reflect upon graduation are regarded as prized indicators of employability. The measurement of throughput should, therefore, not be relegated to a numbers-crunching exercise where throughput is used as a performance indicator of success without considering whether graduateness is in place. This is because employers place a high premium on graduateness as a measure of employability because of the association of this indicator with the qualities of innova- 
tion, efficacy and resilience (Coetzee et al. 2012).

Even though there are several conceptualizations of graduateness the following are worth noting for purposes of this paper. Graduateness is associated, inter alia, with the following graduate competencies: professionalism, dependability, the ability to cope with uncertainty, the ability to work under pressure, the ability to think strategically, the ability to communicate and interact with other, either through networking or as a team member, written and oral skills, ICT skills, creativity and self-confidence, effectiveness and time-management skills and the ability to learn and accept responsibility (Coetzee et al. 2012:14).

Bridgstock (2009:32) uses the employability-oriented model to present the view of graduateness being about evincing the ability to 'proactively navigate the world of work and self-manage the career building process'. Within the public sector, it means preparation for jobs in areas of current scarce skills with generic skills and specialized skills to be immediately effective in the workplace. The private sector conceives of graduateness as preparation in generic skills to be immediately effective in the workplace and an additional competency that would entail the ability to create own employment (Coetzee et al. 2012).

SETA further defines graduateness as preparation in life skills to enter the world of work with ease and to become productive rapidly. Professional associations state that curricula should be broadened to include soft skills as part of the repertoire of graduateness. This conceptualization of graduateness is aligned to providing support that takes into account the match between the contextual realities of Higher Education and a social justice agenda which, for purposes of this discussion, can be linked to a critical emancipatory approach (Mahlomaholo 2005).

Higher Education Institutions generally associate graduateness with the ability to evince academic success. This would serve as an indication of preparation to enter the labour market and at the same time assume active citizenship in society at large while ensuring future knowledge generation and possible participation in global citizenry (Coetzee et al. 2012).

\section{The Global Citizenry Perspective}

The International Labour Organization (ILO) provides two supportive factual observations. Firstly, they draw attention to the fact that, employment mobility 


\section{P.B. Neo Maseko \& Tennyson Mgutshini}

for graduates can be multiplied through their fluency in English. Similarly, the ILO has shown that no less than $87 \%$ of all business within the commercial field is conducted in English and that all other official languages have been extracted from many syllabi. The preference for English over other languages is seen as a key way of preparing UNISA graduates for wider global relevance. (Altbach et al. 2009; Gacel-Avila 2005; Dawoody 2011) have referred to this dilemma as the 'global citizenry perspective'. Simply expressed, this perspective argues assertively that retaining English as the preferred Language offers unparalleled opportunities for students to seek out, not only local employment but global career paths as well.

\section{South African Graduates and Opportunities for Global Citizenry}

After the global financial meltdown that started in 2007, the world has seen the rise of a new world order, with traditional global leaders such the United States of America (USA) and the United Kingdom (UK) seeing a downward trend in their fiscal fortunes (The World Bank 2012). In contrast to this largely pessimistic trajectory for traditional developed countries, there is wide excitement about Africa's rise, with it contributing the world's five fastest growing economies out of the ten fastest growing GDPs from 2011 to 2013. One of the most noteworthy challenges within such a context relates to the need for the creation of enough employment for the region's growing population. Global mobility in the job-market has meant that graduates from all over the world are entering the same employment markets as graduates from South Africa and like never before, the quality of South African graduates has been the focus of critical evaluation. Redfern (2013) identifies two primary questions that emerge from this discourse - firstly, whether South Africa's graduates possess the necessary skills to be 'employment-ready' and secondly, whether these graduates have been adequately transformed by their university education to become responsible global citizens who produce more than they consume in all facets of their lives?

These above-specified explorations of graduate contributions in a range of finance and commerce domains has been mirrored by a discourse within academia which has posed serious questions about whether universities are in fact producing graduates who have the wide-ranging competencies to be globally marketable as employees. This is further substantiated by a wide 
recognition that the achievement of long-term economic growth is centrally dependent on investment in a highly skilled workforce. With respect to this, the British Council (2013) presents empirical evidence based on research in, Ghana, Kenya, Nigeria and South Africa which concludes that:

Despite expanding access to universities in Sub-Saharan Africa, there are widespread concerns about the quality of provision and graduates' preparation for the workplace, with some blaming poor graduate outcomes on graduates' poor numeracy and language of commerce skills (The British Council 2013: 12).

Debates on the use of English as the primary language of instruction relate squarely to the latter and are similarly related to graduates' mobility in their employability. South African graduates' ability to obtain jobs outside their country of education rates among the lowest in Sub-Saharan Africa, a number of reasons have been quoted within literary sources and these include: - (a) limited proficiency in English, the global language of commerce. (b) lowerthan-average numeric proficiency. South Africa's matriculation system has often been compared to other schooling systems in the world and many educational analysts have drawn attention to the fact that, on average, South African educated pre-university students fall considerably short in education levels compared to their counterparts from other countries (Taylor 2012). In essence, they enter university with a lower than desired mastery of the numeracy and language-related core competencies that are regarded as prerequisites for academic success. This analytical insight, however, pays attention to the issue of language to the exclusion of that of numeracy.

As alluded to earlier, the debates about 'competence in English' and its role as a pre-requisite for graduate success have, in recent years, been widely contested. Asserted viewpoints range from, the decoloniality-motivated views that argue that, a continued reliance on English as the language of teaching and learning in South Africa is no more than an unwelcome perpetuation of colonial ideology. Furthermore, this viewpoint sees a need for the promotion of the other local languages as a necessary alternative that will promote a stronger national identity for citizens (Alexander 2010). Contrary to this view, there are many, including (Huisman et al. 2012; Chang 2006; Seidel \& Moritz 2009) who argue that English is by far the most universally important language, such that any economic success at a global level is dependent on the country's 


\section{P.B. Neo Maseko \& Tennyson Mgutshini}

ability to produce graduates who are exceptionally fluent in English.

While significance is accorded to the ideal of a counter-hegemonic strategy of mother tongue instruction and its concomitant cultural and ideological ramifications, the view posited in this paper is that of cognizance of the current reality in pursuance of a critical emancipatory agenda. This entails recognition of the fact that the academic performance (and success) of students hinges upon their ability to encode and decode texts in English. We further argue that, in view of the South African reality of the connection of English language proficiency to students' graduateness, employability and, by association, social mobility as well as access to global citizenry, it seems reasonable to adopt a critical emancipatory approach as a responsive measure to this paradigmatic paradox. This would entail equipping (which, in this context would have connotations of empowerment) students with competencies that are valued as indicators of academic success, graduateness and employability, such as language proficiency and knowledge configuration skills. The ideological orientation of this paper thus leans towards a transformative and critical emancipatory perspective which should take into account the current contextual realities. This view holds that an appropriate response to the multi-layered challenges of the South African Higher Education landscape would be to focus on positioning students for academic success, graduateness, employability and competent participation in the various arenas where English is valued as the language of communication.

\section{References}

Alexander, N. 2010. Schooling in and for the New South Africa. Focus on Learning and Teaching: Galvanising Education. The Journal of the Helen Suzman Foundation 56: 7 - 13.

Altbach, P.G., L. Reisberg \& L.E. Rumbley 2009. Trends in Global Higher Education Tracking: An Academic Revolution Trends in Global Higher Education. A Report prepared for the UNESCO 2009 World Conference on Higher Education. SIDA/SAREC.

https://doi.org/10.1163/9789004406155 020

Barrie, S.C. 2006. Understanding what we Mean by the Generic Attributes of Graduates. Higher Education 51: 215 - 241. https://doi.org/10.1007/s10734-004-6384-7 
Bernstein, B. 1990. Class, Codes and Control: The Structuring of Pedagogic Discourse. London: Routledge.

https://doi.org/10.4324/9780203011263

Björkman, B. 2011. English as a Lingua Franca in Higher Education: Implications for EAP. Ibérica 22: 79.

Boden, R. \& Nevada, M. 2010. Employing Discourse: Univrsitities and Graduate Employability. Journal of Education Policy 25,1: 37 - 54.

https://doi.org/10.1080/02680930903349489

Bridgstock, R. 2009. The Graduate Attributes we've Overlooked: Enhancing Graduate Employability through Career Management Skills. Higher Education Research and Development 28, 1: 31 - 34.

https://doi.org/10.1080/07294360802444347

Chang, J. 2006. Globalization and English in Chinese Higher Education.

World Englishes 25,3-4:513 - 525. Available at:

https://doi.org/10.1111/j.1467-971X.2006.00484.x

Coetzee, M., J. Botha, N. Eccles, N. Hotzhauzen \& H. Nienable (eds.) 2012.

Developing Student Graduateness and Employablity: Issues,

Provocations, Theory and Practical Guidelines. Randburg: Knowles Publishing.

Cummins, J. 1996. Negotiating Identities: Education for Empowerment in a Diverse Society. Los Angeles: Californian Association for Bilingual Education.

Dawoody, A.R. 2011. The Global Participant Observer Emergence, Challenges and Opportunities. Innovation 16: 1 - 31.

Gacel-Avila, J. 2005. The Internationalisation of Higher Education: A Paradigm for Global Citizenry. Journal of Studies in International Education 9: 121 - 136. https://doi.org/10.1177/1028315304263795

Grant, R. \& S.D. Wong 2003. Barriers to Literacy for Language-minority Learners: An Argument for Change in the Literacy Education Profession. Journal of Adolescent \& Adult Literacy 46,5: 386 - 394.

https://doi.org/10.1598/JAAL.46.5.2

$\mathrm{Hu}, \mathrm{G}$. \& J. Lei 2014. English-medium Instruction in Chinese Higher Education: A Case Study. Higher Education 67: 551 - 567.

https://doi.org/10.1007/s10734-013-9661-5

Huisman, J., H. de Boer \& P.C.P. Bótas 2012. Where do We Go from Here? The Future of English Higher Educationn. Higher Education Quarterly 66,4: 341 - 362. https://doi.org/10.1111/j.1468-2273.2012.00532.x 
Martínez, R.A. 2010. Spanglish as Literacy Tool : Toward an Understanding of the Potential Role of Spanish English Code - Switching in the Development of Academic Literacy: What is Spanglish? Research in the Teaching of English 45,2: 124 - 150.

Matenjie, T. 2010. MT Instruction. Focus on Learning and Teaching: Galvanizing Eeducation. The Journal of the Helen Suzman Foundation 56: $38-43$.

McGregor, K. 2014. Higher Education in the $20^{\text {th }}$ Year of Democracy. University World News. The Global Window on Higher Education 317.

McNamee, S.J. \& R.K. Miller 2004. The Meritocracy Myth. North Carolina: Rowman and Littlefield.

Moeketsi, R.M.H. \& T. Mgutshini 2014. A Comparative Time Review of Recruitment and Retention at a Univerisity in South Africa. African Higher Education Research 20,1:246 - 264.

Nicherson, C. 2005. English as a Lingua Franca in International Business Contexts. English for Specific Purposes 24, 4: 367 - 380.

https://doi.org/10.1016/j.esp.2005.02.001

Norton, B., 2010. Perspectives Identity, Literacy, and English-Language Teaching. TESL Canada Journal 281, 1: 1 - 13.

https://doi.org/10.18806/tesl.v28i1.1057

Okombo, O. Towards a Non-adversarial Relationship between English and Indigenous African Languages. In Pfaffe, J.P. (ed.): Local Languages in Education, Science and Technology. Proceedings of the $2^{\text {nd }}$ National Symposium on Language and Policy Formation.

Seidel, K. \& J. Moritz 2009. Changes in Ethiopia's Language and Education Policy - Pioneering Reforms? In Proceedings of the $16^{\text {th }}$ International Conference of Ethiopian Studies.

Short, D. \& S. Fitzsimmons 2007. Double the Work: Challenges and Solutions to Acquiring Language and Academic Literacy for Adolescent English Language Learners: A Report to Carnegie Corporation of New York. Washington, DC: Alliance for Excellent Education.

Stone, J., 2009. Higher Education in a Web 2.0 World. World 15:52. Available at:

http://www.jisc.ac.uk/media/documents/publications/heweb20rptv1.pdf Taylor, N. 2012. National Report. Pretoria: National Education Evaluation and Development Unit.

Thorpe, K. 2002. Multi-lingualism and Minority Languages in South Africa: 
A Discussion Paper. Zeitschrift für Kultuurwissenschaften 13.

Woolf, E. 2005. The Language Factor on Discourse Development and Education in Africa. Paper presented at athe Symposium on Language development in Africa. Moi University, Edlore. Kenya.

UNESCO 2003. Education in a Multi-lingual World. Paris. UNESCO

P.B. Neo Maseko

Post-doc Research Fellow

University of the Free-State

MasekoPBN@ufs.ac.za

Mgutshini Tennyson

Professor in Public Health College of Human Sciences The University of South Africa. mgutst@unisa.ac.za 